\title{
Glomerular Organization of the
} Antennal Lobes of the Diamondback Moth, Plutella xylostella L.

\author{
Xizhong Yan ${ }^{1}$, Zhiyu Wang ${ }^{1}$, Jiaoxin Xie ${ }^{1}$, Caiping Deng ${ }^{2}$, Xuejun Sun ${ }^{1,3 *}$ and Chi Hao ${ }^{1 *}$ \\ ${ }^{1}$ Department of Entomology, Agricultural College, Shanxi Agricultural University, Taigu, China, ${ }^{2}$ Department of Entomology, \\ Forestry College, Shanxi Agricultural University, Taigu, China, ${ }^{3}$ Department of Experimental Oncology, Cross Cancer Institute, \\ University of Alberta, Edmonton, AB, Canada
}

OPEN ACCESS

Edited by:

Angel Acebes,

Centro de Investigaciones Biomédicas de Canarias (CIBICAN), Spain

Reviewed by:

Shigehiro Namiki,

The University of Tokyo, Japan

Xin-Cheng Zhao,

Henan Agricultural University, China

Sylvia Anton,

Institut National de la Recherche Agronomique (INRA), France

*Correspondence:

Xuejun Sun

xjsun@ualberta.ca

Chi Hao

sxauhc@163.com

Received: 14 October 2018

Accepted: 14 January 2019

Published: 05 February 2019

Citation:

Yan X, Wang Z, Xie J, Deng C, Sun X and Hao C (2019) Glomerular Organization of the Antennal Lobes of the Diamondback Moth, Plutella

xylostella L. Front. Neuroanat. 13:4.

doi: 10.3389/fnana.2019.00004
The antennal lobe of the moth brain is the primary olfactory center processing information concerning pheromones and plant odors. Plutella xylostella is a major worldwide pest of cruciferous vegetables and its behavior is highly dependent on their olfactory system. However, detailed knowledge of the anatomy and function of the P. xylostella olfactory system remains limited. In the present study, we present the 3-Dimentional (3-D) map of the antennal lobe of $P$. xylostella, based on confocal microscopic analysis of glomerular segmentation and Neurobiotin backfills of Olfactory Receptor Neurons (ORNs). We identified 74-76 ordinary glomeruli and a macroglomerular complex (MGC) situated at the entrance of the antennal nerve in males. The MGC contained three glomeruli. The volumes of glomeruli in males ranged from $305.83 \pm 129.53$ to $25440.00 \pm 1377.67$ $\mu \mathrm{m}^{3}$. In females, $74-77$ glomeruli were found, with the largest glomerulus ELG being situated at the entrance of the antennal nerve. The volumes of glomeruli in females ranged from $802.17 \pm 95.68$ to $8142.17 \pm 509.46 \mu \mathrm{m}^{3}$. Sexual dimorphism was observed in anomalous supernumerary, anomalous missing, shape, size, and array of several of the identified glomeruli in both sexes. All glomeruli, except one in the antennal lobe (AL), received projections of antennal ORNs. The glomeruli PV1 in both sexes received input from the labial palp nerve and was assumed as the labial pit organ glomerulus (LPOG). These results provide a foundation for better understanding of coding mechanisms of odors in this important pest insect.

Keywords: antennal lobe, glomeruli, olfactory system, confocal microscopy, antennal backfill, anatomical reconstruction, Plutella xylostella

\section{INTRODUCTION}

In insects, the olfactory system plays a highly important role in detecting odorants involved in sexual communication, social integration, host recognition, and escaping from enemies over a distance (Lopes et al., 2002; Gill et al., 2013; Sun et al., 2014; Xu et al., 2016). The antennae are the primary olfactory organ and bear several types of sensilla (Galizia and Rossler, 2010; Yan et al., 2014, 2017a). The most prominent sensillum types have olfactory functions and contain olfactory receptor neurons (ORNs), which send projections directly to the antennal lobe $(\mathrm{AL})$, the primary olfactory center of the insect brain.

Typically, the insect AL is composed of many spheroidal neuropilar units, called glomeruli that house synaptic contacts between receptor axons and AL interneurons (Hansson and Stensmyr, 2011). The arrangement, size, and number of AL glomeruli are species-specific, allowing the 
identification of individual glomeruli according to the size, shape, and its position. The number of glomeruli in the AL varies from fewer than 15 glomeruli in Scaphoideus titanus (Rossi Stacconi et al., 2014) to more than 1,000 in locusts (Rospars, 1988). Most insect species studied to date have 40-160 glomeruli arranged in a single or double layer (Rospars, 1983; Hansson and Anton, 2000). In many insect species, sexual dimorphism with respect to specific glomeruli is observed, e.g., the $\mathrm{AL}$ of male Lepidoptera contains enlarged glomeruli that form the macroglomerular complex (MGC) at the entrance of the antennal nerve into the $\mathrm{Al}$ in Mamestra brassicae (Rospars, 1983) and Trichoplusia ni (Todd et al., 1992). All ORNs that express the same specific odorant receptor converge onto the same glomerulus (Vosshall and Wong, 2000). Odor representation from ORNs to projection neurons (PNs) is generally conserved (Seki et al., 2017). Different PN classes target dendrites to distinct olfactory glomeruli, whereas PNs of the same class exhibit indistinguishable anatomical and physiological properties ( $\mathrm{Li}$ et al., 2017). In the Drosophila olfactory circuit, 50 ORN classes and $50 \mathrm{PN}$ classes form synaptic connections in 50 glomerular compartments in the antennal lobe, each of which represents a discrete olfactory information-processing channel (Wu et al., 2017). The one ORN class to one glomerulus and to one PN class relationship in the Drosophila olfactory system is likely an extreme situation as, in other species, this may vary as the glomeruli numbers vary dramatically. In male moths, the MGC receives and processes information regarding the female sex pheromone, calcium imaging in Heliothis virescens confirms that sex pheromone responses are restricted to the male-specific MGC, plant odors to ordinary glomeruli (Galizia et al., 2000), and sex pheromone-specific receptor neurons arborize in the MGC (Hansson et al., 1992; Ochieng et al., 1995).

The diamondback moth (DBM; Plutella xylostella; Lepidoptera: Plutellidae) is a major worldwide pest of cruciferous vegetables. Because of the intensive and extensive application of insecticides for the control of $P$. xylostella, the species has become one of the most resistant insect pests in the world (Sarfraz et al., 2005; Furlong et al., 2013; Wang et al., 2013; Li et al., 2016). This resistance has prompted increasing efforts to identify new, natural approaches to control this insect. One of these approaches focuses on understanding the plant chemistry that plays a major role in the moth acceptance or rejection of host plants. However, relatively little is known about the olfactory pathways in the central nervous system of this insect. To better understand the general organization and the functional significance of AL glomeruli in odor processing, we generated the first digital 3-D reconstruction of the AL in P. xylostella through Confocal Laser Scanning Microscopy (CLSM) reconstruction of the $\mathrm{AL}$ and backfilling of the antennal neurons. The atlas will serve as a template for future analysis of physiological responses in morphologically identified glomeruli in this pest insect.

\section{MATERIALS AND METHODS}

\section{Insects}

Plutella xylostella were reared at the temperature of $25^{\circ} \mathrm{C}$, relative humidity of $75 \%$ and photoperiod of $(\mathrm{L}: \mathrm{D}=14: 10)$ in the Insect Neuroethology \& Sensory Biology laboratory, Shanxi Agricultural University. Pupae were individually segregated into test tubes according to sex, and recently emerged (1-2-days-old) female and male adults of $P$. xylostella were used in this study.

\section{Palp and Antennal Backfills}

Six male and six female moths were anesthetized with carbon dioxide and immobilized using double-sided adhesive tape, and the ventral part of the head was exposed. The antennae or the palp of one side of the moth were cut near the base, and the remainder of the segments were inserted for $30 \mathrm{~min}$ in an appropriately sized micropipette tip filled with $2 \%$ Neurobiotin (Neurobiotin Tracer, Vector Laboratories, Burlingame, USA) solution. After the micropipette was removed, the preparations were then incubated at $4^{\circ} \mathrm{C}$ for $2 \mathrm{~h}$ in a humidified and dark box for diffusion of the dye. Subsequently, the brains were dissected out in $4 \%$ paraformaldehyde in phosphate buffer $(\mathrm{PB}$, $0.1 \mathrm{M}, \mathrm{pH}$ 7.2) under a dissecting microscope, and the isolated brains were fixed in the same fixative at $4^{\circ} \mathrm{C}$ for $1-2$ days for batch processing. After rinsing three times with $0.1 \%$ Triton $\mathrm{X}$ 100 in $0.1 \mathrm{M} \mathrm{PB}$, the brains were incubated in $2 \mu \mathrm{g} / \mathrm{ml}$ Alexa488 Streptavidin (Molecular Probes, Life Technologies, USA) solution in PBS for 1-2 days and then in $10 \mu \mathrm{g} / \mathrm{ml}$ Propidium Iodide (Sigma) solution for $30 \mathrm{~min}$ at room temperature. The brains were dehydrated in an ascending ethanol series of 30,50, 75,95 , and $100 \%$ alcohol and then embedded in DPX (Sigma) after a brief xylene transition.

\section{Confocal Laser Scanning Microscopy}

Twelve whole-mounts of brains were imaged with a Zeiss LSM 710 confocal laser scanning microscope equipped with multiple laser lines that permitted the visualization of structures labeled with Alexa-488 and labeling of Propidium iodide used in this study. CLSM imaging was conducted using 488-nm excitation wavelength for the Alexa-488 Streptavidin labeling, and the Alexa-488 signal was collected between 490 and $560 \mathrm{~nm}$. The propidium iodide signals, which label the nucleus of neurons, were excited with a $561 \mathrm{~nm}$ laser line and collected between 567 and $596 \mathrm{~nm}$. For overview scanning of the whole brain and detailed scanning of the antennal lobe, a $40 \times$ (NA1.3) oil objective was used with a sampling rate matching the Nyquist sampling rate with a pinhole setting of 1 Airy Unit. Image data were captured as serial stacks (pixel dwelling time of 0.39 $\mu \mathrm{s}$, pinhole $1 \mathrm{AU}$, step size $0.4-0.45 \mu \mathrm{m})$. Generally, each brain requires an image stack of 300-500 slices (depending on the mounting orientation of the brain) of images with $2048 \times 2018$ pixels [with a pixel dimension of $0.104 \times 0.104 \times 0.4 \mu \mathrm{m}(\mathrm{x}, \mathrm{y}$, z)].

\section{3-D Reconstructions and Identification of Glomeruli}

All confocal image stacks were viewed and processed with the 3 D reconstruction software Imaris (vers: 8.4.0, Bitplane, Zurich, Switzerland). Glomeruli in the ALs were entirely demarcated by manually tracing the outline of each glomerulus in every other section of the stack file. The outlines of the glomeruli could be easily defined by a combination of many characteristics in 
the images: auto-fluorescence of the antennal lobe structure, propidium iodide-labeled glia cells that usually surround the glomeruli (Figures 1A,C) (Yan et al., 2017b) and signals from the Neurobiotin backfills of the ORNs (Figures 1B,C). Such manually delineated lines were subsequently used to generate surface rendered glomeruli structure, and the software generated the volume as well as sphericity of each individual glomerulus
(Figures 1D-F). Two analysts independently analyzed each data set to reduce possible errors and bias. Glomeruli were identified according to their location, shape, and size. The glomerular nomenclature used was adopted from previous publications of other groups (Ignell et al., 2005; Solari et al., 2016). Namely, each glomerulus was marked by one or two capital letters indicating the general position: anterior $(\mathrm{A})$, posterior $(\mathrm{P})$, ventral $(\mathrm{V})$,
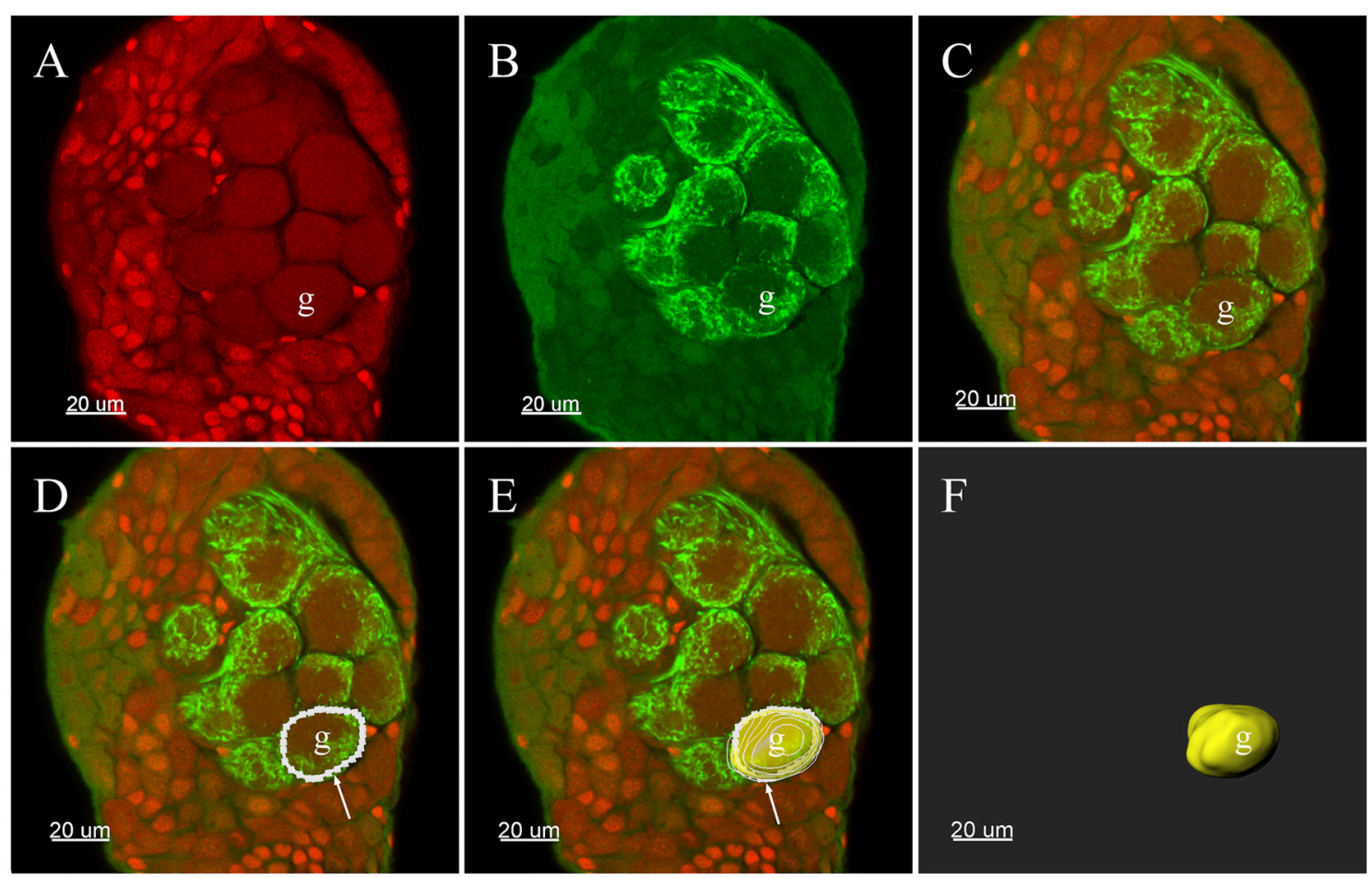

FIGURE 1 | Three-D reconstructions of a glomerulus in the antennal lobe of Plutella xylostella demonstrating the procedures for the 3-D reconstruction. (A) One raw confocal image of the antennal lobe with Propidium lodide labeling the cell nucleus. (B) Neurobiotin ${ }^{T M}$ backfilling of the antennal sensory innervations, green indicates signal from the Neurobiotin of the projections of ORNs. (C) Propidium lodide and Neurobiotin stainings merged together from (A) and (B). (D) Tracing the outline of one glomerulus in a single plane was carried out manually in Imaris. (E) After repeating the tracing of other layers of the glomerulus, the glomerulus was surface rendered (yellow) with the outlines (white). (F) The surface render of one glomerulus. The arrow indicates outline of a glomerulus. g, Glomerulus.
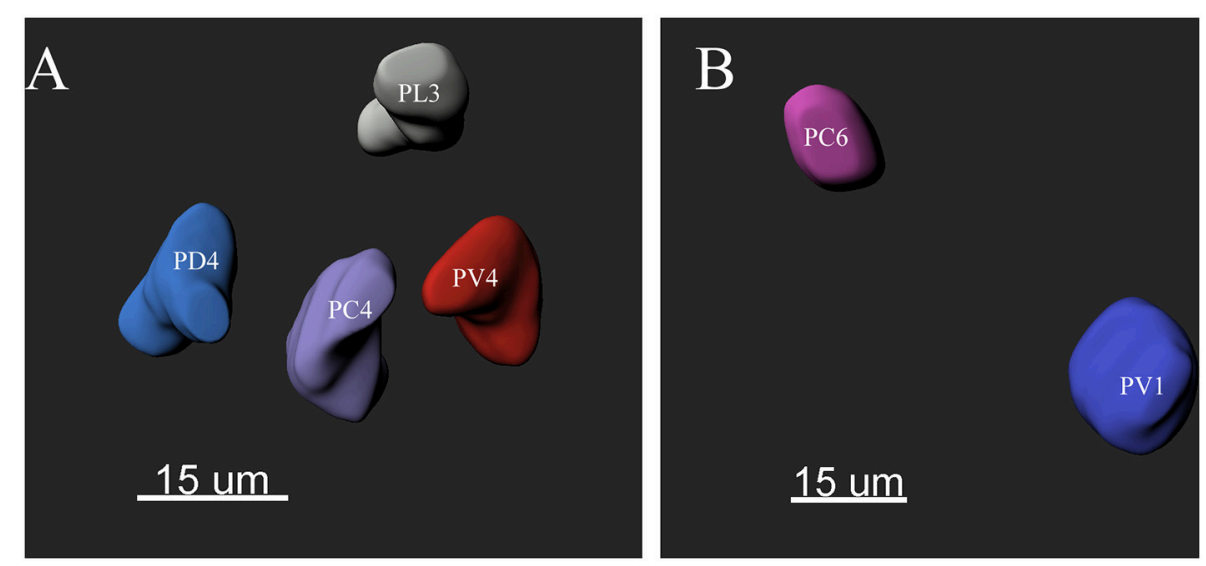

FIGURE 2 | The morphology of the glomeruli in a female antennal lobe of P. xylostella. (A) Irregular glomeruli (sphericity: PV4: 0.852; PC4: 0.842; PL3: 0.834 and PD4: 0.832). (B) Regular glomeruli (sphericity: PC6 0.946 and PV1: 0.950). 

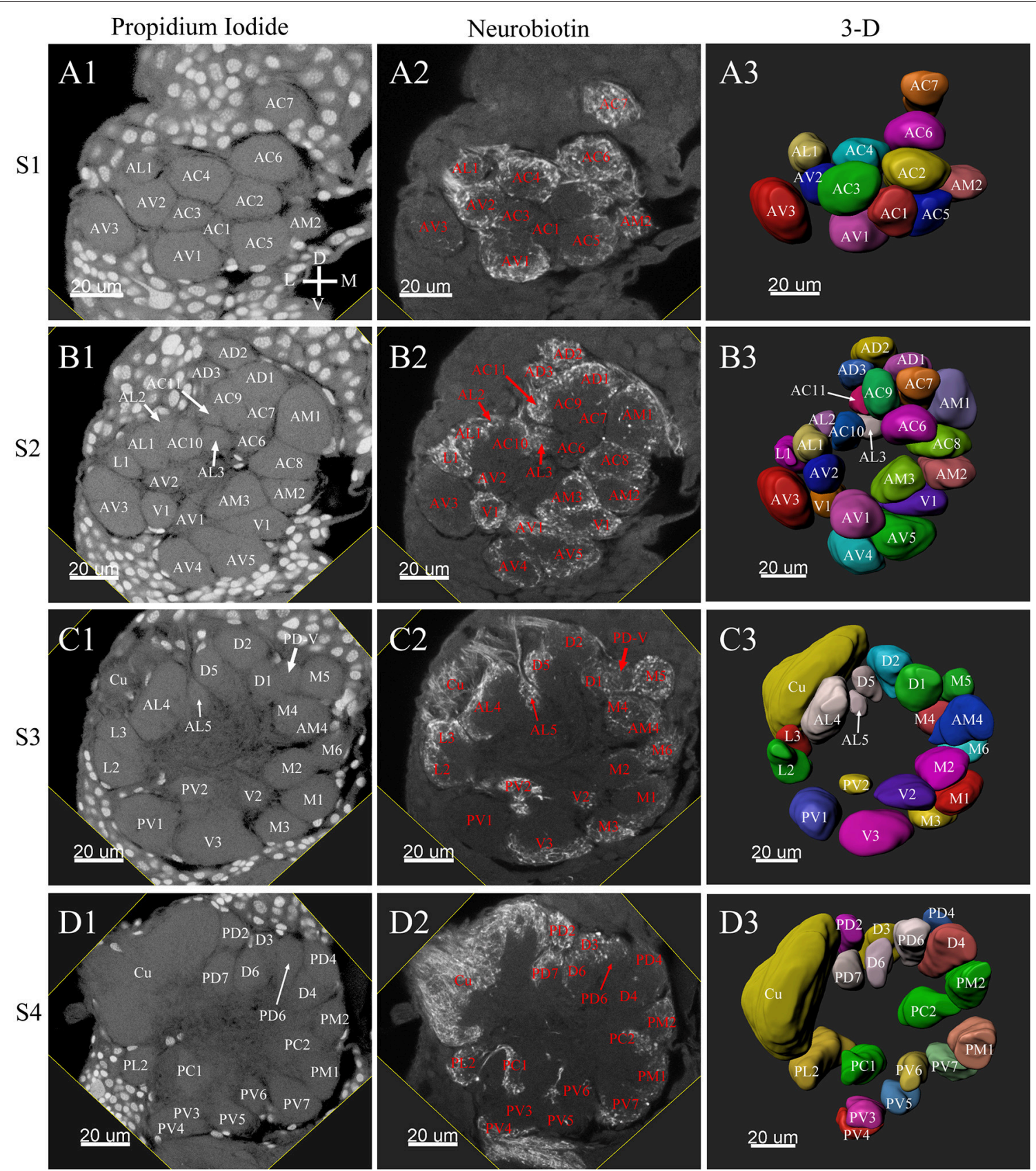

FIGURE 3 | Frontal glomeruli reconstructions of a male antennal lobe. For clarity, the entire antennal lobe was separated into 7 consecutive arbitrarily reconstructed series (S1-S7). This panel shows the front 4 series (last 3 series will be demonstrated in Figure 4): (A1-A3) The first level, S1, where was the most anterior layer. The (B1-B3) shows the second level, S2. The (C1-C3) depicts the third level, S3. The (D1-D3) shows the fourth level, S4. (A1-D1) Series of frontal confocal sections of Propidium lodide labels; (A2-D2) Neurobiotin backfilling of the antennal sensory innervations. (A3-D3) Frontal view of 3-D reconstructions of the antennal lobe. Each identified glomerulus was named according to the monocultures as described in the text and numbered, from the most anterior to the most posterior in each layer. Additionally, different colors were randomly assigned to each glomerulus. Cu, cumulus; D, dorsal; L, lateral; M, medial; V, ventral.

dorsal (D), lateral (L), medial (M), and central (C). Letters were followed by numbers to indicate glomerulus presentation order from the most anterior to the most posterior in the same region. Additionally, the glomeruli were identified using several structural landmarks such as (1) general contour structure of the AL; (2) the entrance of the antennal nerves; (3) the brain orientations, and (4) specific, easily identifiable glomeruli such as putative MGC, enlarged glomeruli in the female, ELG, PV1, etc. The same nomenclature structure was used for both the male and female glomeruli. Although we did not systematically 

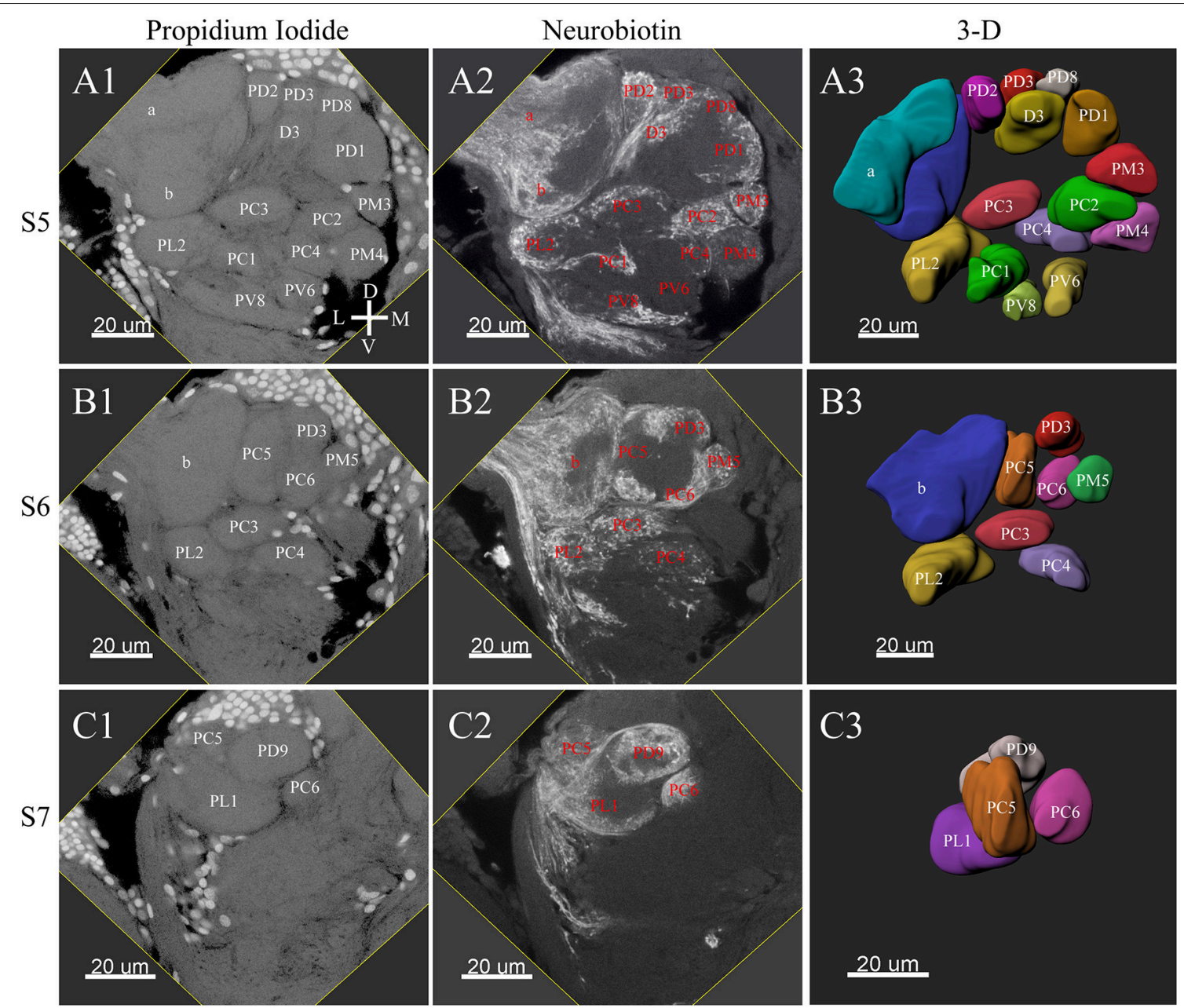

FIGURE 4 | Posterior glomeruli reconstructions of a male antennal lobe, series S5-7. Row (A1-A4) shows the fifth level, S5. Row (B1-B4) demonstrates the sixth level, S6. The row (C1-C4) shows the most posterior glomeruli, the seventh level, S7. (A1-C1) Series of frontal confocal sections of Propidium lodide. (A2-C2) Neurobiotin backfilling of antennal sensory innervations. (A3-C3) Frontal views 3-D reconstructions. Each identified glomerulus was named and numbered from the most anterior to the most posterior as described in text. D, dorsal; L, lateral; M, medial; V, ventral.

compare the glomeruli from the male and female AL, every attempt was made to have glomeruli in both sexes in similar positions and sizes to have comparable glomeruli annotation. This visualization based matching presented some inherited limitations that the same glomeruli name may not present the homologous glomeruli. Every glomerulus was assigned with a random color for the purpose of visualization. The MGC received served as an essential orientation landmark for the male AL. Final output data were stored in TIFF format and annotated using Photoshop CS software (Adobe, San Jose, CA, USA).

\section{Statistical Analyses}

The following parameters were measured: total number of glomeruli and volume of glomeruli of the AL. The volume of each individual glomerulus was calculated with the SPSS statistical software package (ver. 13.0, SPSS incorporated, Chicago, Illinois), and values are presented as the mean $\pm \mathrm{SD}$.

\section{RESULTS}

\section{Three-Dimensional Reconstruction of the $A L$}

The ALs of P. xylostella were mostly sphere-shaped structures located in the front most part of the brain. Numerous glomeruli were found in the AL (Supplementary Videos 1-3). Generally, the majority of the glomeruli were spherical or elliptical in shape. The sphericities (a measure of how round a structure is) of the glomeruli were in the range of $0.7-0.96$ (while a perfect sphere is 1). Only few glomeruli per antennal lobe displayed irregularities with a lower sphericity (Figure 2 ). The glomeruli were mostly located at the periphery of the lobe in a single layer and generally, the anterior glomeruli were more densely packed than the posterior glomeruli (Figures 3-8). Most glomeruli were uniform in shape, size, and relative position, based on the comparison of different ALs and therefore could be identified and recognized individually. Only glomeruli four and five displayed 

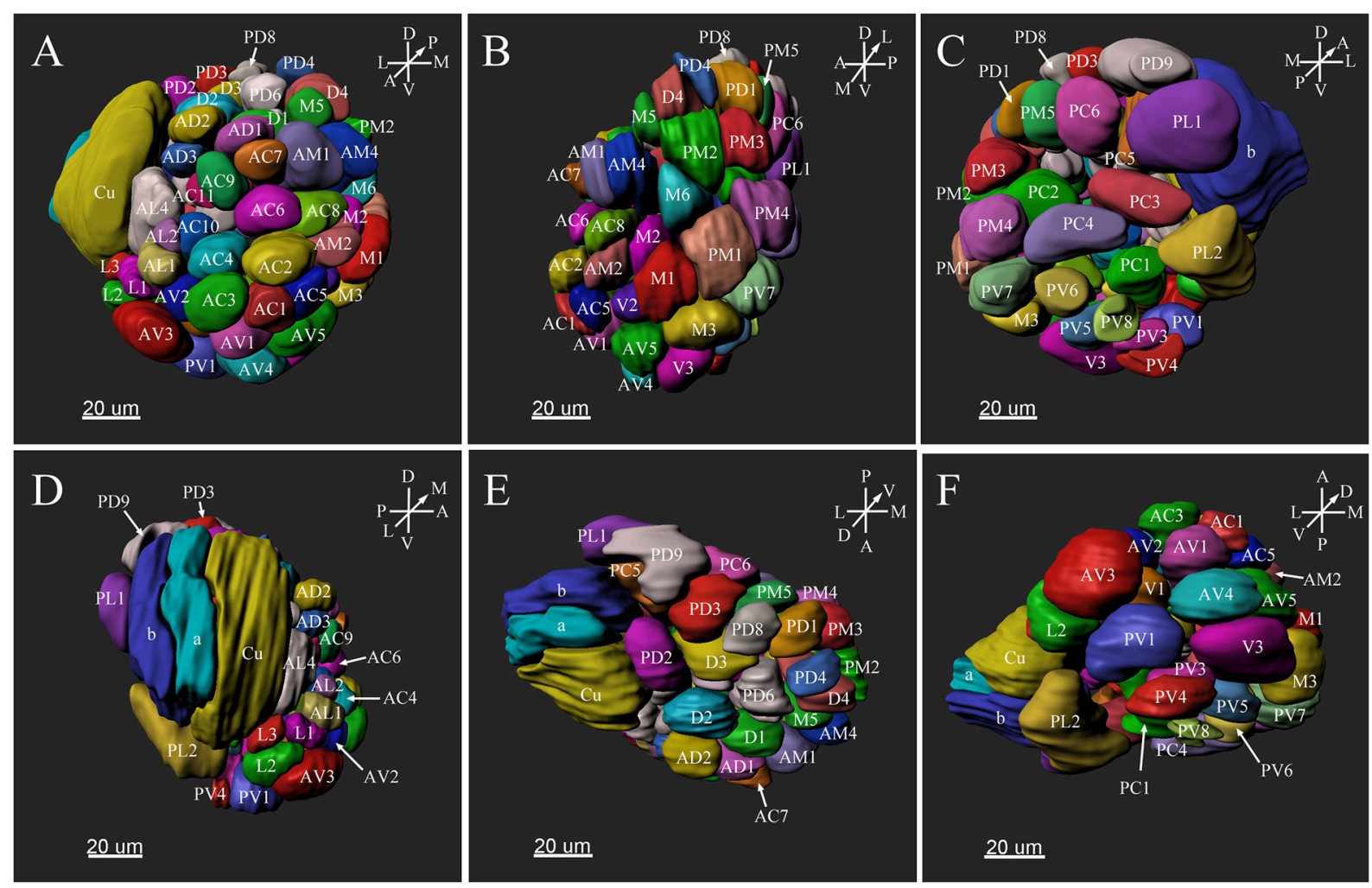

FIGURE 5 | Three-dimensional reconstruction of the entire antennal lobe of a male P. xylostella. (A) Frontal view. (B) Medial view. (C) Posterior view. (D) Lateral view. (E) Dorsal view. (F) Ventral view. A, anterior; D, dorsal; L, lateral; M, medial; P, posterior; V, ventral.

some anomalies (missing or extra) (Table 3). The glomeruli were named and color-coded as descripted previously. Each identified glomerulus was named and numbered in the order in which the layers appear from the most anterior to the most posterior.

Tracing neurons from the antenna reliably labeled to the ipsilateral AL, and projections of ORNs formed densely-packed regions identifiable as glomeruli (Figures 3A2-D2, 4A2-C2, 6A2-D2, 7A2-C2).

\section{Male ALs}

A putative Macro-Glomerular Complex (MGC) structure and 74-76 ordinary glomeruli were found in the six male ALs studied (Table 1; Figures 3-5; Supplementary Video 2).

\section{The MGC}

The putative MGC structure was found close to the entrance of the antennal nerve of male P. xylostella. It contained three glomeruli: the cumulus and glomeruli a and b (Figures 3D1-3, 4A1-3, B1-3, 5D). They were clearly separated from the array of ordinary glomeruli, based on their shape, volume, and location. As the most anterior glomerulus of the putative MGC, the cumulus exhibited a cylindrical shape, but the ventral part was flattened (Figure 3C3). The cumulus was the largest glomerulus in the $\mathrm{AL}$, and the volume was $25440.00 \pm 1377.67$ $\mu \mathrm{m}^{3}$ (Table 1). Glomerulus a of the putative MGC positioned posteriorly from the cumulus, and the volume was 12540.00 $\pm 968.50 \mu \mathrm{m}^{3}$. Glomerulus $\mathrm{b}$ of the putative MGC positioned posteriorly from glomerulus a and was $16640.00 \pm 1818.79 \mu \mathrm{m}^{3}$ in volume (Figure 5D; Table 1). All three glomeruli in the MGC received projections of ORNs from the antenna (Figures 3D2, 4A2,B2). The cumulus and glomeruli a and b in MGC were regarded as very important landmark glomeruli.

\section{Ordinary Glomeruli}

The maximum number of ordinary glomeruli was 76 , which was found in one male AL. M5, V3, PV2 and PV6 were missing in some ALs within our samples; M5 was found in five of the six ALs, V3 was found in four of the six ALs, PV2 was found in two of the six ALs, and PV6 was found in three of the six ALs. The other 72 glomeruli could be systematically identified in all six ALs (Table 3). Seven glomeruli in males had volumes smaller than $1000 \mu \mathrm{m}^{3}$ (Figure 9). Glomerulus AL2 was the smallest ordinary glomerulus, with a volume of $305.83 \pm 129.53 \mu \mathrm{m}^{3}$ (Table 1), and this glomerulus was located in the anterior-lateral region of the AL (Figures 3B1-3, 5A). Most glomeruli showed volumes between 1000 and 3000 $\mu \mathrm{m}^{3}$, with 32 glomeruli volumes between 1000 and $2000 \mu \mathrm{m}^{3}$, and 23 between 2000 and $3000 \mu \mathrm{m}^{3}$ in males. In males, 17 glomeruli had volumes larger than $3000 \mu \mathrm{m}^{3}$, including 14 ordinary glomeruli and the 3 glomeruli in the MGC (Figure 9). Glomerulus PL2 was the largest ordinary glomerulus, with a volume of $9166.50 \pm 1631.38 \mu \mathrm{m}^{3}$ (Table 1). PL2 neighbored 


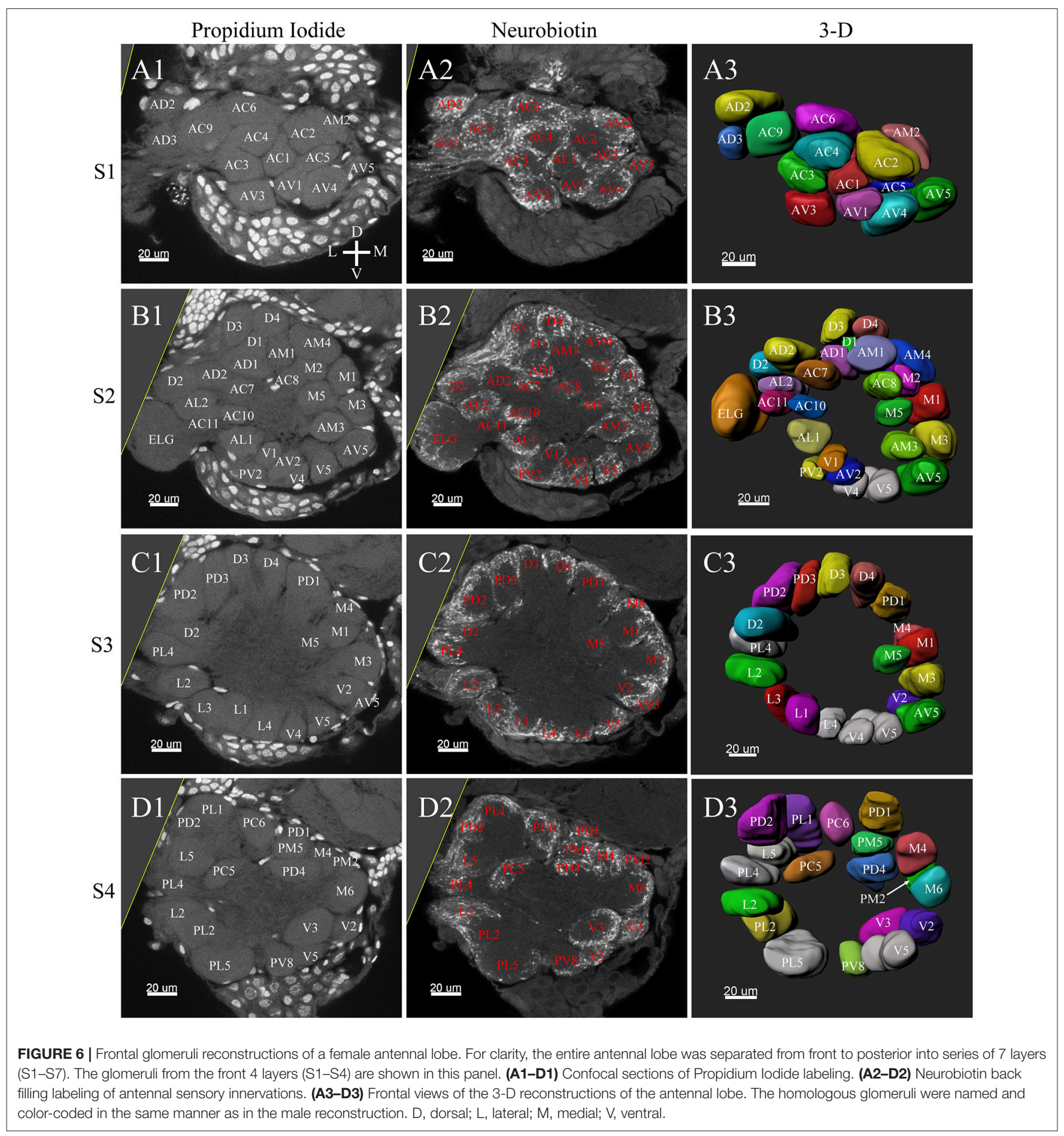

the MGC and was located in the posterior-lateral region of the AL (Figures 3D1-3, 5D). Antennal backfills revealed staining in many, but not in all glomeruli. Glomerulus PV1 was found without ORN branches (Figure 3C2). Back filling of the labial palps with Neurobiotin performed similarly, revealed only one glomerulus (PV1) was innervated by sensory neurons from the labial palps (Figure 10B). This glomerulus had a relatively large size $\left(4573.00 \pm 658.85 \mu^{3}\right)$ and was located at the ventral side of the ALs (Figures 5A,F; Table 1). It is worth to note that the back filling of the labial palps nerve labels the PV1 of boths side of the brain, therefore, unlike the other glomeruli, PV1 receives information from both labial palps. The glomeruli AL2, PL2 and PV1 were regarded as landmark glomeruli in male ALs. 

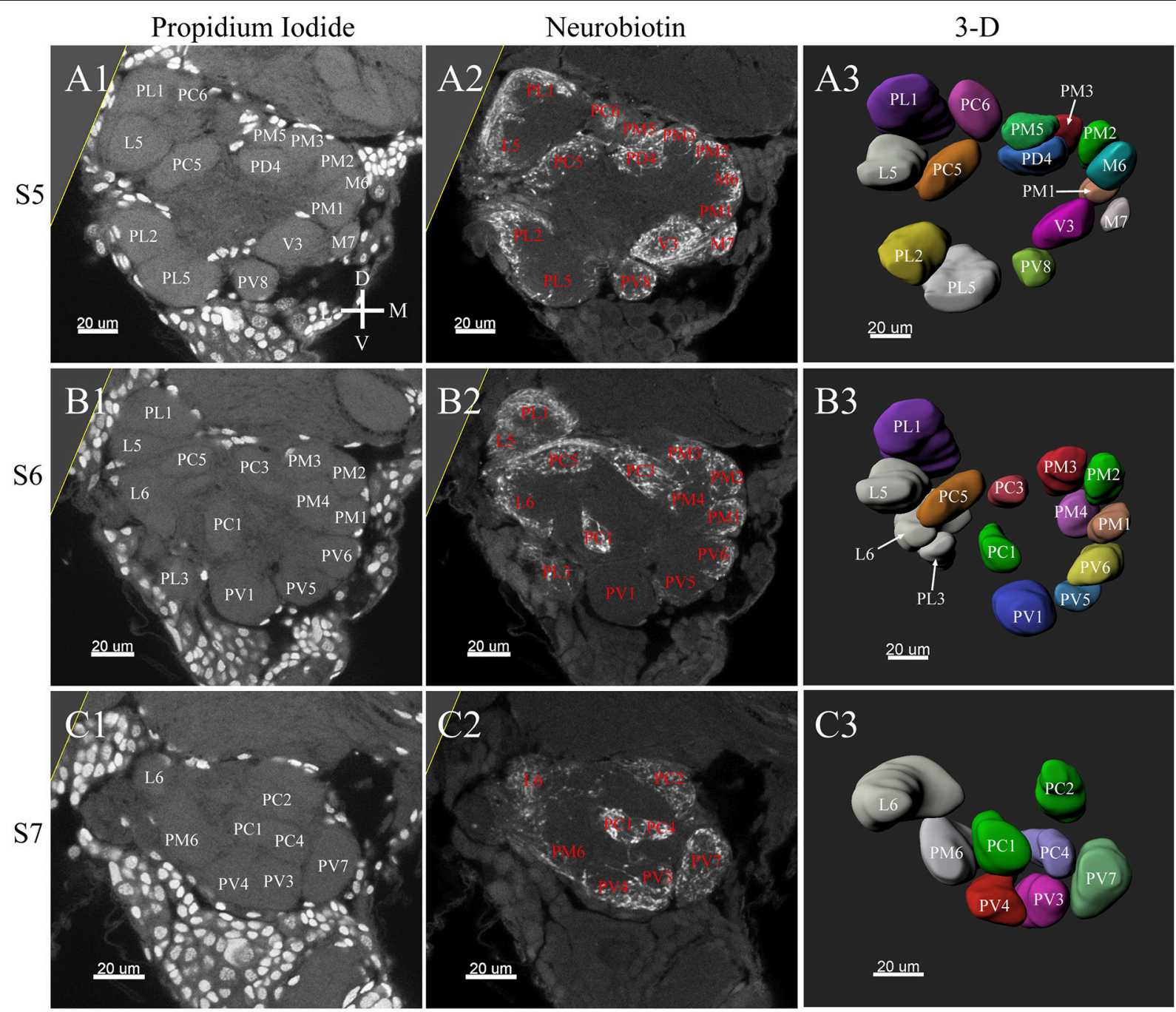

FIGURE 7 | Posterior glomeruli reconstructions of a female antennal lobe, series S5-7. (A1-C1) Series of frontal confocal sections of Propidium lodide labeling. (A2-C2) Neurobiotin labeling of the antennal sensory innervations. (A3-C3) Front views of the 3-D reconstructions of the antennal lobe. Each identified glomerulus was named and as described before. D, dorsal; L, lateral; M, medial; V, ventral.

\section{Female ALs}

In the six female ALs, 74-77 glomeruli were found (Table 2; Supplementary Video 3). Similar to the male, there was a slight variation in glomeruli numbers: 77 glomeruli were found in the ALs of one female. M3 was found in three of the six AL, M6 was found in two of the six ALs, AM4, M5, and PL3 were found in five of the six ALs, respectively. Nevertheless, 72 glomeruli could be systematically identified in all six ALs (Table 3). Four glomeruli in females had volumes smaller than $1000 \mu^{3}$ (Figure 9). AD3 was the smallest glomerulus, and the volume was 802.17 $\pm 95.68 \mu \mathrm{m}^{3}$ (Table 2), and this glomerulus was located in the anterior-dorsal region of the AL (Figures 6A1-3, 8A). In females, 24 glomeruli had volumes between 1,000 and 2,000 $\mu \mathrm{m}^{3}$; the volumes for 26 glomeruli were between 2,000 and $3,000{\mu \mathrm{m}^{3}}^{3}$; and an additional 23 glomeruli had volumes larger than $3,000 \mu \mathrm{m}^{3}$ (Figure 9). Corresponding to the location of the
MGC in the male, the largest glomerulus ELG was located in the anterior-lateral region of the $\mathrm{AL}$ and close to the entrance of the antennal nerve (see ELG in Figures 6B1-3, 8A), and the volume of this glomerulus was $8,142.17 \pm 509.46 \mu \mathrm{m}^{3}$ (Table 2). All the glomeruli received antennal receptor neurons with the exception of PV1 glomerulus (Figure 7B2), which received neurons from the labial palps, similar to the males (Figure 10C). The glomerulus was large $\left(4,961.33 \pm 705.50 \mu \mathrm{m}^{3}\right)$ and was located at the ventral side of the AL (Figures 8D,F; Table 2). The glomeruli ELG, AD3, and PV1 were regarded as landmark glomeruli in female ALs.

\section{Landmark Glomeruli}

There were several distinct glomeruli in both sexes which were used as landmarks for glomeruli identification and matching. For the male AL, in addition to the above-mentioned putative 

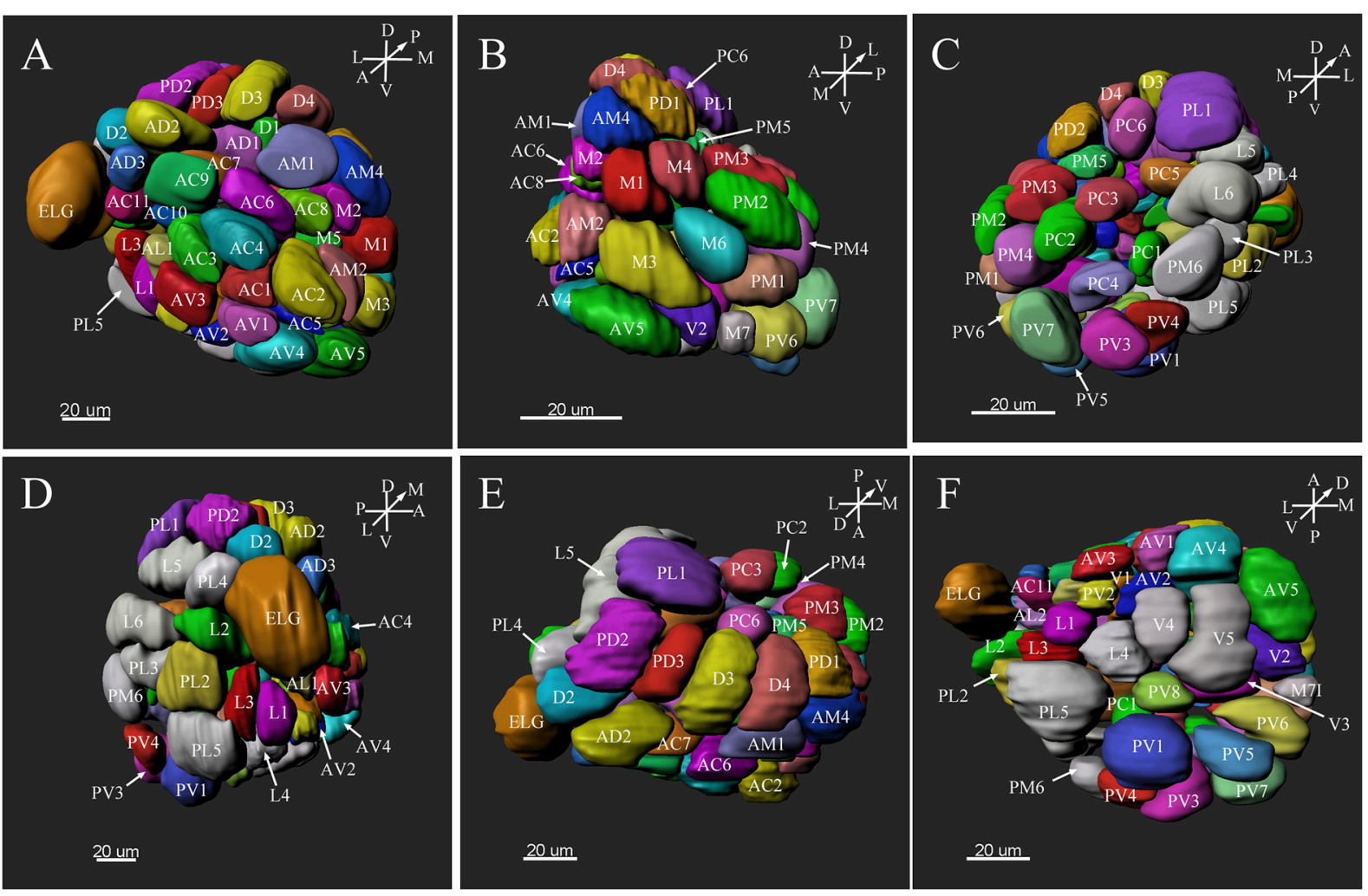

FIGURE 8 | Three-dimension reconstruction of the glomeruli from the entire antennal lobe of a female P. xylostella. (A) Frontal view. (B) Medial view. (C) Posterior view. (D) Lateral view. (E) Dorsal view. (F) Ventral view. A, anterior; D, dorsal; L, lateral; M, medial; P, posterior; V, ventral.

MGC, glomeruli AL2, PV1, PL2, AV3, AL4, PC1, PC4, and PD9 could be easily identified either by their marked locations, shapes or sizes. For example, the glomerulus AV3 was a flattened, elliptical sphere, located in the anterior-lateral region of the $\mathrm{AL}$ and under the MGC (Figure 5A). AL4 neighbored the MGC, and was larger than other ordinary glomeruli in this region (Figure 5A). PC1 was a slender cylinder, and located in the posterior-lateral region of the AL (Figure 5C). PC4 was a long elliptical sphere, located in the posterior-central region of the AL (Figure 5C). The larger glomerulus PD9 was located in the most posterior region of the $\mathrm{AL}$, and close to the MGC (Figure 5C).

In the female ALs, in addition to the morphologically evident glomeruli ELG, AD3, and PV1, glomeruli AC2, AV5, PL5, and PL1 were also easily recognizable. AC2 was oblong in shape, and located in the most anterior region of the AL (Figure 8A). AV5 and PL5 were among the largest glomeruli in the ventral regions of the AL (Figures 8A,D). PL1 was the third largest glomerulus, and located in the posterior-central region of the $\mathrm{AL}$ (Figure 8C).

\section{Comparison of Male and Female ALs}

Comparing the glomerular organization of the AL of male and female $P$. xylostella demonstrated both sexes possessed approximately the same number of $\mathrm{AL}$ glomeruli. Within the same sex, most glomeruli proved to be highly consistent in size, shape and position in the ALs. Nevertheless, a few anomalous glomeruli were missing in some ALs of both sexes (Table 3). Additionally, although the majority of glomeruli were between 1,000 and $3,000 \mu^{3}$ in volumes in both sexes, there are some size distribution differences in the male and female glomeruli (Figure 9). The peak number of glomeruli in the males is with a volume between 1,000 and $2,000 \mu \mathrm{m}^{3}$ while, in the females, the peak number of the glomeruli was with a volume between 2,000 and 3,000 $\mu \mathrm{m}^{3}$ (Figure 9).

Some special glomeruli were present in both sexes in the same position. For example, the largest glomeruli MGC in males and ELG in females occupy the same domain in both sexes. The second largest glomerulus PL2 in males and PL5 in females was situated under the MGC and ELG, respectively (Figures 5D, 8D; Tables 1, 2). The smallest glomerulus AL2 in males and AD3 in females was located in the anterior region of the $\mathrm{AL}$ and near to the entrance of the antennal nerve (Figures 5A, 8A; Tables 1, 2). Furthermore, PV1 was the only glomerulus not innervated by the antennal nerve, but by the labial palpus nerve in both sexes (Figure 10). This glomerulus was relatively large and located at the ventral side of the AL (Figures 5F, 8F). The glomerulus PV1 in the male was smaller than that in the females. Additionally, unlike other glomeruli in the AL which received neuronal input from ipsilateral antennal nerves, this glomeruli received innervation from both sides of the labial palpus nerve (Figure 10). 
TABLE 1 | Volumes of glomeruli (mean \pm SE) in the antennal lobe (AL) of male Plutella xylostella.

\begin{tabular}{|c|c|c|c|c|c|c|c|c|}
\hline Glomerulus & Volume $\left(\mu \mathrm{m}^{3}\right)$ & $n$ & Glomerulus & Volume $\left(\mu \mathrm{m}^{3}\right)$ & $n$ & Glomerulus & Volume $\left(\mu \mathrm{m}^{3}\right)$ & $n$ \\
\hline AC1 & $1455.83 \pm 263.79$ & 6 & AV5 & $3811.17 \pm 249.27$ & 6 & PD9 & $4705.33 \pm 846.81$ & 6 \\
\hline AC2 & $2302.67 \pm 535.07$ & 6 & L1 & $1190.67 \pm 172.22$ & 6 & PL1 & $5489.33 \pm 956.17$ & 6 \\
\hline AC3 & $1785.17 \pm 387.84$ & 6 & L2 & $3303.83 \pm 898.02$ & 6 & PL2 & $9166.50 \pm 1631.38$ & 6 \\
\hline AC4 & $1697.83 \pm 147.12$ & 6 & L3 & $2053.17 \pm 952.25$ & 6 & PV1 & $4573.00 \pm 658.85$ & 6 \\
\hline AC5 & $1238.17 \pm 87.83$ & 6 & M1 & $2870.00 \pm 721.05$ & 6 & $\underline{P V 2}$ & $926.50 \pm 101.11$ & 2 \\
\hline AC6 & $1572.17 \pm 248.01$ & 6 & M2 & $2425.33 \pm 428.86$ & 6 & PV3 & $3616.50 \pm 486.37$ & 6 \\
\hline AC7 & $1238.67 \pm 178.11$ & 6 & M3 & $4030.83 \pm 209.03$ & 6 & PV4 & $1371.17 \pm 274.65$ & 6 \\
\hline AC8 & $1957.67 \pm 338.50$ & 6 & M4 & $1779.67 \pm 310.97$ & 6 & PV5 & $1621.83 \pm 137.32$ & 6 \\
\hline AC9 & $1669.33 \pm 263.82$ & 6 & $\underline{\text { M5 }}$ & $1043.40 \pm 159.47$ & 5 & $\underline{P V 6}$ & $3018.67 \pm 504.12$ & 3 \\
\hline $\mathrm{AC} 10$ & $919.00 \pm 90.10$ & 6 & M6 & $2342.17 \pm 160.17$ & 6 & PV7 & $3178.00 \pm 457.11$ & 6 \\
\hline $\mathrm{AC} 11$ & $983.00 \pm 179.51$ & 6 & D1 & $1620.17 \pm 305.26$ & 6 & PV8 & $996.50 \pm 218.69$ & 6 \\
\hline AM1 & $2472.33 \pm 215.57$ & 6 & D2 & $2085.17 \pm 430.69$ & 6 & PM1 & $2894.50 \pm 684.68$ & 6 \\
\hline AM2 & $1671.67 \pm 289.38$ & 6 & D3 & $2218.17 \pm 412.21$ & 6 & PM2 & $2529.00 \pm 553.86$ & 6 \\
\hline AM3 & $1728.667 \pm 216.59$ & 6 & D4 & $2243.83 \pm 306.97$ & 6 & PM3 & $2346.83 \pm 451.21$ & 6 \\
\hline AM4 & $1572.50 \pm 238.83$ & 6 & D5 & $777.67 \pm 252.99$ & 6 & PM4 & $2456.67 \pm 291.34$ & 6 \\
\hline AL1 & $1269.17 \pm 325.48$ & 6 & D6 & $1575.50 \pm 189.71$ & 6 & PM5 & $1867.00 \pm 99.62$ & 6 \\
\hline AL2 & $305.83 \pm 129.53$ & 6 & $\mathrm{~V} 1$ & $1053.00 \pm 578.49$ & 6 & PC1 & $2192.33 \pm 622.91$ & 6 \\
\hline AL3 & $1239.17 \pm 159.30$ & 6 & V2 & $2584.83 \pm 431.54$ & 6 & PC2 & $2704.83 \pm 459.46$ & 6 \\
\hline AL4 & $2931.33 \pm 156.19$ & 6 & $\underline{\mathrm{V} 3}$ & $3735.00 \pm 348.08$ & 4 & PC3 & $3177.33 \pm 1084.69$ & 6 \\
\hline AL5 & $675.83 \pm 272.42$ & 6 & PD1 & $2156.17 \pm 383.89$ & 6 & PC4 & $3469.50 \pm 1377.57$ & 6 \\
\hline AD1 & $1724.50 \pm 234.17$ & 6 & PD2 & $2490.17 \pm 219.98$ & 6 & PC5 & $3301.50 \pm 1555.46$ & 6 \\
\hline AD2 & $1799.83 \pm 172.00$ & 6 & PD3 & $1978.17 \pm 268.26$ & 6 & PC6 & $2547.67 \pm 377.95$ & 6 \\
\hline AD3 & $1102.83 \pm 117.33$ & 6 & PD4 & $1987.50 \pm 250.18$ & 6 & $\mathrm{Cu}$ & $25440.00 \pm 1377.67$ & 6 \\
\hline AV1 & $2127.67 \pm 611.54$ & 6 & PD5 & $1463.17 \pm 279.17$ & 6 & a & $12540.00 \pm 968.50$ & 6 \\
\hline AV2 & $1423.67 \pm 282.43$ & 6 & PD6 & $1848.33 \pm 213.48$ & 6 & $b$ & $16640.00 \pm 1818.79$ & 6 \\
\hline AV3 & $2923.33 \pm 779.33$ & 6 & PD7 & 1681.33 土 151.52 & 6 & & & \\
\hline AV4 & $2534.00 \pm 432.38$ & 6 & PD8 & $1253.67 \pm 124.44$ & 6 & & & \\
\hline
\end{tabular}

Underlined texts indicate missing/abnormal glomeruli.

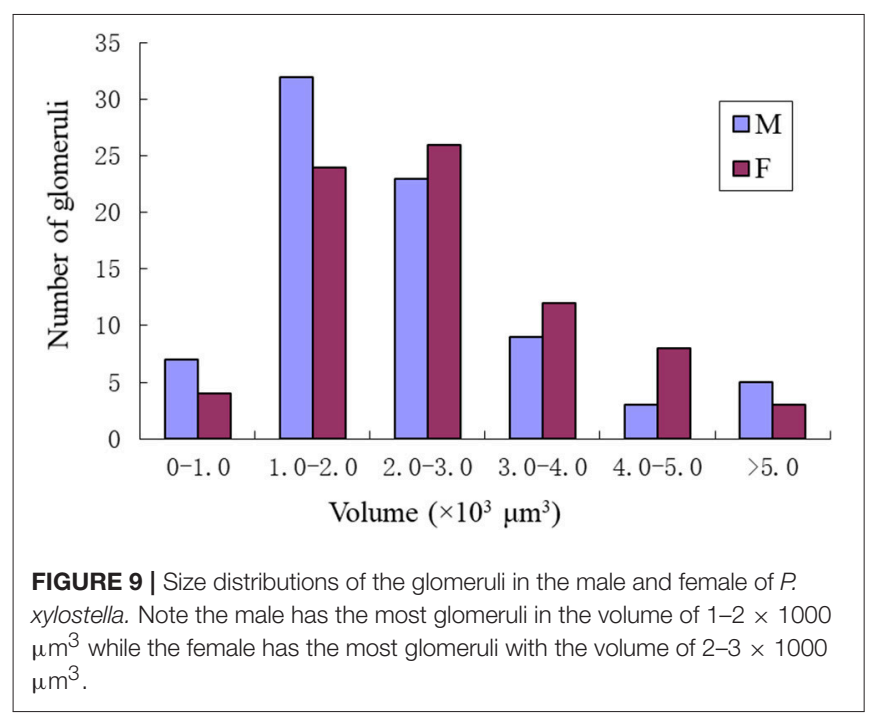

\section{DISCUSSION}

In this paper, we presented a complete 3-D reconstruction of the glomerular organization of $P$. xylostella, based on the systematic anatomical matching of glomeruli within and between the sexes. We found most glomeruli were apparently isomorphic between sexes. However, significant differences occurred in the presence, absence, sizes, or locations of some glomeruli.

\section{Number of Glomeruli in $P$. xylostella}

Similar to other investigated insect species, the glomeruli are distributed around a central fiber core (Rospars and Hildebrand, 1992, 2000; Berg et al., 2002; Greiner et al., 2004). The number of glomeruli can vary greatly depending on the species (Rospars, 1988; Huetteroth and Schachtner, 2005); in Lepidoptera, the number of glomeruli ranges from 60 to 70 (Rospars, 1983; Rospars and Hildebrand, 1992, 2000; Berg et al., 2002; Sadek et al., 2002; Greiner et al., 2004; Masante-Roca et al., 2005; Namiki et al., 2014). The number of glomeruli found in P. xylostella is slightly higher than in the other moth species previously mentioned, which is not surprising because these species belong to very distantly related families. However, even closely related species have significant differences in the number of glomeruli. Generally, one glomerulus is the target site for one ORN type (Couto et al., 2005). The number of glomeruli is different in different insect species because they possess different lifestyles. When comparing two closely related species, Cydia molesta has 

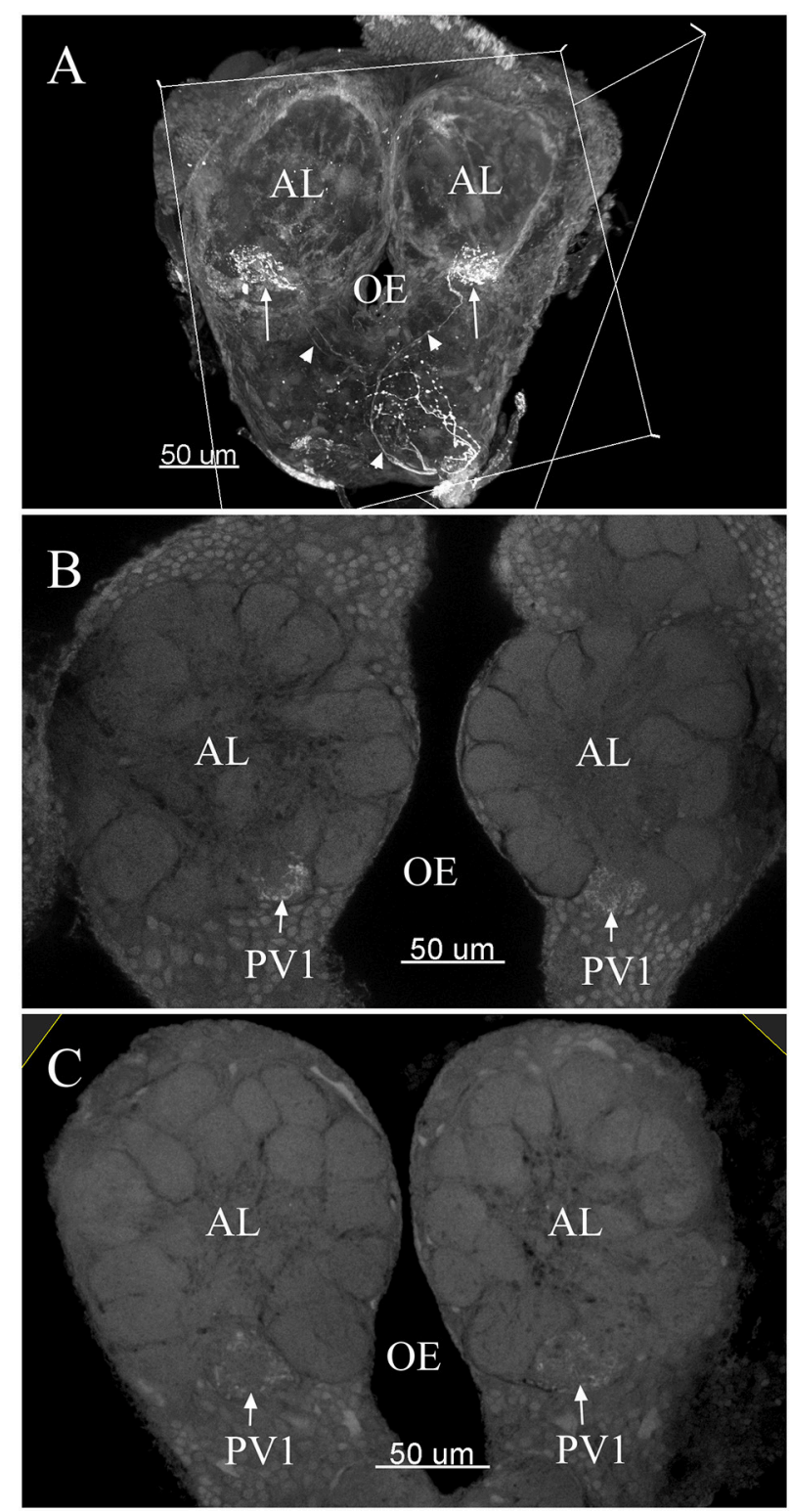

FIGURE 10 | The confocal images of the terminals of sensory neurons originating from the labial palpus projecting bilaterally to the AL. Note the back-fillings were performed on a single side of the brains (A). PV1 ordinary glomerulus in male (B) and PV1 in female (C). The arrow indicates nerve terminals project bilaterally into the ordinary glomerulus. The arrowhead indicates nerve fibers. AL, antennal lobe; OE, esophagus.

fewer glomeruli than Lobesia botrana, and the former is an oligophagous insect species, while the latter is a polyphagous species; therefore, C. molesta may require a narrower range of olfactory cues to identify their hosts than that of L. botrana (Varela et al., 2009). When insects lack glomeruli caused by some factors, e.g., mutagenesis causes, these insects lose corresponding olfactory functions. Orco mutant ants (disrupted orco, a gene required for the function of all ORs) lack most of the $\sim 500$ glomeruli found in wild-type ants and are unable to perceive pheromones (Trible et al., 2017). Generally, insects with complex lifestyles (e.g., social insects) have relatively large numbers of glomeruli and use a large variety of chemical cues (Galizia et al., 1999; Kleineidam et al., 2005). P. xylostella are oligophagous insects (Renwick et al., 2006), and they have a relatively narrow range of olfactory cues. Thus, $P$. xylostella has lower numbers of glomeruli than those of the social insects studied to date. Nevertheless, comparing with other moths studied so far, $P$. xylostella shows a higher number of glomeruli suggesting a neuronal base for a more complex olfactory behavior.

\section{Macroglomeruli in the Male P. xylostella}

MGC in the AL structure based on sex pheromone communication has been observed in a wide range of insects, such as cockroaches (Boeckh et al., 1987), bees (Brockmann and Brückner, 2001), ants (Nishikawa et al., 2008), fruit flies (Solari et al., 2016), and moths (Anton and Homberg, 1999; Hansson and Anton, 2000; Masante-Roca et al., 2005; Varela et al., 2009; Nirazawa et al., 2017). The MGC consists of 1-7 glomeruli situated closely together and is near the entrance of the antennal nerve in males (Hansson, 1995; Masante-Roca et al., 2005). In Lepidoptera, the number of MGC structures is different in different species, comprising one large glomerulus in L. botrana males (Masante-Roca et al., 2005), two large glomeruli in M. brassicae (Rospars, 1983), three glomeruli in Helicoverpa assulta males (Berg et al., 2002), Manduca sexta (Rospars and Hildebrand, 2000) and Spodoptera littoralis (Ochieng et al., 1995), and four glomeruli in Agrotis ipsilon (Greiner et al., 2004). We found the putative MGC contained three glomeruli in the males of $P$. xylostella. One of these glomeruli resembled the cumulus, which has been found in several other moths and processes sex pheromone information (Hansson and Anton, 2000; Masante-Roca et al., 2005; Varela et al., 2009; Nirazawa et al., 2017), while two other glomeruli, a and b, were positioned posteriorly and close to the cumulus.

The number of MGC structures has been reported correlated to the number of pheromone components in the respective species (Hansson et al., 1992; Ochieng et al., 1995; Berg et al., 1998; Varela et al., 2009). In H. virescens, the MGC contains four glomeruli and receptor neurons that respond to the major sex pheromone component (Z11-16:AL) projected to the large glomerulus cumulus, the second pheromone component (Z9$14: \mathrm{AL})$ projected to the dorso-medial glomerulus, and the interspecific signals (Z11-16:AC and Z11-16:OH) projected to two ventrally located glomeruli (Berg et al., 1998). Intriguingly, the sex pheromone $P$. xylostella comprises 3 components $[(Z)$ 11-hexadecenal (Z11-16:Ald), (Z)-11-hexadecenyl acetate (Z1116:OAc) and (Z)-11-hexadecen-1-ol (Z11-16:OH)] (Bignon et al., 2010). Z11-16:Ald and Z11-16:OAc are essential for attraction of male moths, Z11-16:OH has a synergistic effect on the two components (Koshihara and Yamada, 1980). Z11-16:Ald and Z11-16:OAc with a 10:90 blend could highly attract male $P$. xylostella, and addition of 1 or $10 \%$ of $\mathrm{Z} 11-16: \mathrm{OH}$ to the blend significantly increased attraction (Bignon et al., 2010). Although the putative MGC contains 3 compartments which match the number of the pheromone components, the projection pattern of receptor neurons tuned to behaviorally active components 
TABLE 2 | Volumes of glomeruli (mean \pm SE) in the antennal lobe (AL) of female Plutella xylostella.

\begin{tabular}{|c|c|c|c|c|c|c|c|c|}
\hline Glomerulus & Volume $\left(\mu \mathrm{m}^{3}\right)$ & $n$ & Glomerulus & Volume $\left(\mu \mathrm{m}^{3}\right)$ & $n$ & Glomerulus & Volume $\left(\mu \mathrm{m}^{3}\right)$ & $n$ \\
\hline AC1 & $1534.83 \pm 310.61$ & 6 & L2 & $3047.00 \pm 292.99$ & 6 & PL2 & $4005.83 \pm 855.69$ & 6 \\
\hline AC2 & $2566.00 \pm 284.95$ & 6 & L3 & $2078.67 \pm 286.74$ & 6 & $\underline{\text { PL3 }}$ & $3210.80 \pm 506.80$ & 5 \\
\hline AC3 & $1669.17 \pm 230.16$ & 6 & L4 & $2593.83 \pm 440.55$ & 6 & PL4 & $2337.33 \pm 472.86$ & 6 \\
\hline AC4 & $1998.33 \pm 263.29$ & 6 & L5 & $4765.83 \pm 858.63$ & 6 & PL5 & $6444.83 \pm 853.09$ & 6 \\
\hline AC5 & $1897.50 \pm 189.55$ & 6 & L6 & $4620.17 \pm 1233.26$ & 6 & PV1 & $4961.33 \pm 705.50$ & 6 \\
\hline AC6 & $1978.33 \pm 298.50$ & 6 & M1 & $3321.17 \pm 658.54$ & 6 & PV2 & $831.17 \pm 374.59$ & 6 \\
\hline AC7 & $1316.17 \pm 204.48$ & 6 & M2 & $1403.17 \pm 139.45$ & 6 & PV3 & $2155.00 \pm 275.59$ & 6 \\
\hline AC8 & $1314.83 \pm 176.87$ & 6 & $\underline{\mathrm{M} 3}$ & $3897.33 \pm 639.76$ & 3 & PV4 & $1762.33 \pm 199.61$ & 6 \\
\hline AC9 & $1751.83 \pm 237.46$ & 6 & M4 & $2038.17 \pm 350.07$ & 6 & PV5 & $2567.00 \pm 234.51$ & 6 \\
\hline AC10 & $992.83 \pm 474.11$ & 6 & $\underline{\text { M5 }}$ & $1498.20 \pm 290.72$ & 5 & PV6 & $3039.67 \pm 180.81$ & 6 \\
\hline $\mathrm{AC} 11$ & $996.33 \pm 108.07$ & 6 & $\underline{\text { M6 }}$ & $2221.50 \pm 123.74$ & 2 & PV7 & $3650.83 \pm 358.35$ & 6 \\
\hline AM1 & $2248.00 \pm 364.24$ & 6 & M7 & $1090.00 \pm 830.53$ & 6 & PV8 & $1564.33 \pm 293.87$ & 6 \\
\hline AM2 & $1776.83 \pm 262.43$ & 6 & D1 & $1026.50 \pm 91.87$ & 6 & PM1 & $2074.67 \pm 347.31$ & 6 \\
\hline AM3 & $1690.83 \pm 919.16$ & 6 & D2 & $2480.83 \pm 441.53$ & 6 & PM2 & $2556.00 \pm 393.95$ & 6 \\
\hline AM4 & $3627.80 \pm 340.08$ & 5 & D3 & $2581.83 \pm 446.73$ & 6 & PM3 & $2316.83 \pm 314.58$ & 6 \\
\hline AL1 & $1941.50 \pm 331.14$ & 6 & D4 & $2939.67 \pm 168.05$ & 6 & PM4 & $2938.00 \pm 374.46$ & 6 \\
\hline AL2 & $1580.33 \pm 212.61$ & 6 & $\mathrm{~V} 1$ & $1146.50 \pm 411.47$ & 6 & PM5 & $2123.00 \pm 576.27$ & 6 \\
\hline AD1 & $2077.17 \pm 395.49$ & 6 & V2 & $2794.83 \pm 370.09$ & 6 & PM6 & $3524.33 \pm 435.40$ & 6 \\
\hline AD2 & $1920.17 \pm 485.95$ & 6 & V3 & $2659.67 \pm 417.20$ & 6 & PC1 & $2265.83 \pm 288.42$ & 6 \\
\hline AD3 & $802.17 \pm 95.68$ & 6 & V4 & $1991.50 \pm 434.75$ & 6 & PC2 & $2825.17 \pm 508.72$ & 6 \\
\hline AV1 & $1545.83 \pm 239.05$ & 6 & V5 & $4018.33 \pm 848.20$ & 6 & PC3 & $3009.67 \pm 449.75$ & 6 \\
\hline AV2 & $1534.67 \pm 339.92$ & 6 & PD1 & $2535.50 \pm 387.61$ & 6 & PC4 & $2648.00 \pm 481.32$ & 6 \\
\hline AV3 & $3360.67 \pm 1337.44$ & 6 & PD2 & $4426.00 \pm 435.29$ & 6 & PC5 & $4972.50 \pm 530.01$ & 6 \\
\hline AV4 & $3381.00 \pm 587.07$ & 6 & PD3 & $2777.67 \pm 464.10$ & 6 & PC6 & $3166.83 \pm 374.56$ & 6 \\
\hline AV5 & $4265.17 \pm 665.29$ & 6 & PD4 & $2381.00 \pm 288.30$ & 6 & ELG & $8142.17 \pm 509.46$ & 6 \\
\hline L1 & $1857.83 \pm 268.85$ & 6 & PL1 & $5997.67 \pm 723.98$ & 6 & & & \\
\hline
\end{tabular}

Underlined texts indicate missing/abnormal glomeruli.

TABLE 3 | Presence of anomalous missing ordinary glomeruli in the antennal lobe (AL) in the six males (M1-6) and females (F1-6) of Plutella xylostella.

\begin{tabular}{|c|c|c|c|c|c|c|c|c|c|c|c|c|c|}
\hline & M1 & M2 & M3 & M4 & M5 & M6 & & F1 & F2 & F3 & F4 & F5 & F6 \\
\hline $\begin{array}{l}\text { Total } \\
\text { number }\end{array}$ & 76 & 74 & 74 & 74 & 74 & 74 & $\begin{array}{l}\text { Total } \\
\text { number }\end{array}$ & 77 & 76 & 75 & 75 & 75 & 74 \\
\hline M5 & + & + & + & - & + & + & AM4 & + & + & + & + & + & - \\
\hline V3 & + & + & + & + & - & - & M3 & + & + & - & - & + & - \\
\hline PV2 & + & - & - & - & - & + & M5 & + & - & + & + & + & + \\
\hline \multirow[t]{2}{*}{ PV6 } & + & - & - & + & + & - & M6 & + & + & - & - & - & - \\
\hline & & & & & & & PL3 & + & + & + & + & - & + \\
\hline
\end{tabular}

+, presentation glomerulus in ALs. -, missing glomerulus in Als.

in P. xylostella has not been studied. We will investigate the structure-function relationships in ORNs with a combination of electrophysiological and anatomical studies of the pheromonespecific ORNs.

\section{Enlarged Glomeruli in the Female $P$. xylostella}

In the female P. xylostella the largest glomerulus, ELG, was found at the entrance of the antennal nerve, a location similar to the one found in males MGC in the antennal lobe. However, this glomerulus was not a complex structure and was much smaller than that of the male MGC. This morphologically distinct glomerulus is not universally present in the female AL. It has previously been described in some female moths, such as Bombyx mori (Koontz and Schneider, 1987), M. sexta (Rospars and Hildebrand, 2000), H. virescens (Berg et al., 2002) but not in S. littoralis (Ochieng et al., 1995), and C. molesta (Varela et al., 2009). Physiological characterization of a PN innervating this glomerulus showed that it processes a self-released sex pheromone in addition to plant volatiles (Ljungberg et al., 1993; Reisenman et al., 2004; Trona et al., 2010). The similarity of the ELG suggests a similar role. It remains to be clarified in $P$. xylostella. 


\section{Other Glomeruli Between the Sexes}

Male moths must locate a mating partner via the dedicated sex pheromones cues. Mated females must identify the suitable oviposition sites via plant volatiles. Therefore, it is not surprising the glomerular structure differs between the sexes. The specific ordinary glomeruli AL2 and PL2 were found close to the MGC. Due to the closeness with the putative MGC of these specific glomeruli, we speculate that these glomeruli might receive and process information regarding the female sex pheromone. In the female ALs, the specific ordinary glomeruli AD3 and PL5 were located near the ELG, and might be responsible for receiving/processing certain female specific behaviors-relative chemical cues (e.g., plant volatiles). More functional studies of these specific ordinary glomeruli are required to elucidate their true functions.

Glomerulus PV1 did not receive projections of the antennal ORNs but received input from the labial palpus nerve, and these glomeruli were located at the ventral of the AL in both sexes and assumed to be the labial pit organ glomerulus (LPOG). The LPOG is found in some species, e.g., the moth Rhodogastria (Bogner et al., 1986), Pieris rapae (Lee and Altner, 1986), M. sexta (Kent et al., 1986), mosquitoes (Anton et al., 2003), C. molesta (Varela et al., 2009), and Helicoverpa armigera (Zhao et al., 2013, 2016). The LPOG is specialized in sensing $\mathrm{CO}_{2}$ (Bogner et al., 1986; Stange, 1992; Guerenstein and Hildebrand, 2008; Ning et al., 2016). Glomerulus PV1 in ALs of P. xylostella is believed to process information on $\mathrm{CO}_{2}$ levels in the environment. Further functional studies (either single sensillum recording or $\mathrm{Ca}$ imaging) are needed to verify if this is the case in this insect species.

\section{REFERENCES}

Anton, S., and Homberg, U. (1999). “Antennal lobe structure," in Insect Olfaction, ed B. S. Hansson (Berlin: Springer-Verlag), 97-124.

Anton, S., van Loon, J. J., Meijerink, J., Smid, H. M., Takken, W., and Rospars, J. P. (2003). Central projections of olfactory receptor neurons from single antennal and palpal sensilla in mosquitoes. Arthropod Struct. Dev. 32, 319-327. doi: 10.1016/j.asd.2003.09.002

Berg, B. G., Almaas, T. J., Bjaalie, J. G., and Mustaparta, H. (1998). The macroglomerular complex of the antennal lobe in the tobacco budworm moth Heliothis virescens : specified subdivision in four compartments according to information about biologically significant compounds. J. Comp. Physiol. A. 183, 669-682. doi: 10.1007/s003590050290

Berg, B. G., Galizia, C. G., Brandt, R., and Mustaparta, H. (2002). Digital atlases of the antennal lobe in two species of tobacco budworm moths, the oriental Helicoverpa assulta (male) and the American Heliothis virescens (male and female). J. Comp. Neurol. 446, 123-134. doi: 10.1002/cne.10180

Bignon, C., Roux-Dosseto, M., Zeigler, M. E., Mattei, M. G., Lissitzky, J. C., Wicha, M. S., et al. (2010). Sex pheromone production and response in Korean populations of the diamondback moth, Plutella xylostella. Entomol. Exp. Appl. 124, 293-298. doi: 10.1111/j.1570-7458.2007.00580.x

Boeckh, J., Ernst, K. D., and Selsam, P. (1987). Neurophysiology and neuroanatomy of the olfactory pathway in the cockroach. Ann. N. Y. Acad. Sci. 510, 39-43. doi: 10.1111/j.1749-6632.1987.tb43464.x

Bogner, F., Boppré, M., Ernst, K. D., and Boeckh, J. (1986). CO 2 sensitive receptors on labial palps of Rhodogastria, moths (Lepidoptera: arctiidae): physiology,
In conclusion, we provided a 3-D reconstruction of the glomerular structure in the $\mathrm{AL}$ of $P$. xylostella. This result provides a foundation for further studying of the olfactory information processing in this important economical pest.

\section{AUTHOR CONTRIBUTIONS}

$\mathrm{XS}, \mathrm{CH}$, and $\mathrm{XY}$ conceived and designed the study. $\mathrm{XY}$ and ZW acquired and analyzed the data. XY, JX, and CD analyzed and interpreted the data. XY and XS wrote the manuscript. $\mathrm{CH}$ provided research funding.

\section{FUNDING}

The One Hundred Talents Programme of Shanxi Province, China (Grant No. 201144), the Natural Science Foundation of Shanxi, China (Grant Nos. 201801D121250 and 2015011072), and Scientific Research Foundation of Shanxi Agricultural University (Grant No. 2014ZZ08) supported this study.

\section{SUPPLEMENTARY MATERIAL}

The Supplementary Material for this article can be found online at: https://www.frontiersin.org/articles/10.3389/fnana. 2019.00004/full\#supplementary-material

Supplementary Video 1 | Video of consecutive frontal sections of a male Plutella xylostella antennal lobe with Propidium lodide and Neurobiotin labeling.

Supplementary Video 2 | Three-dimensional reconstruction of a male antennal lobe of Plutella xylostella.

Supplementary Video 3 | Three-dimensional reconstruction of a female antennal lobe of Plutella xylostella. fine structure and central projection. J. Comp. Physiol. A. 158, 741-749. doi: $10.1007 / \mathrm{BF} 01324818$

Brockmann, A., and Brückner, D. (2001). Structural differences in the drone olfactory system of two phylogenetically distant Apis species, A. florea and A. mellifera. Naturwissenschaften 88, 78-81. doi: 10.1007/s0011400 00199

Couto, A., Alenius, M., and Dickson, B. J. (2005). Molecular, anatomical, and functional organization of the Drosophila olfactory system. Curr. Biol. 15, 1535-1547. doi: 10.1016/j.cub.2005.07.034

Furlong, M. J., Wright, D. J., and Dosdall, L. M. (2013). Diamondback moth ecology and management: problems, progress, and prospects. Annu. Rev. Entomol. 58, 517-541. doi: 10.1146/annurev-ento-120811-153605

Galizia, C. G., Mcilwrath, S. L., and Menzel, R. (1999). A digital threedimensional atlas of the honeybee antennal lobe, based on optical sections acquired by confocal microscopy. Cell Tissue Res. 295, 383-394. doi: 10.1007/s004410051245

Galizia, C. G., and Rossler, W. (2010). Parallel olfactory systems in insects: anatomy and function. Annu. Rev. Entomol. 55, 399-420. doi: 10.1146/annurev-ento-112408-085442

Galizia, C. G., Sachse, S., and Mustaparta, H. (2000). Calcium responses to pheromones and plant odours in the antennal lobe of the male and female moth Heliothis virescens. J. Comp. Physiol. A 186, 1049-1063. doi: 10.1007/s003590000156

Gill, K. P., Van, W. E., Macmillan, D. L., and Elgar, M. A. (2013). Density of antennal sensilla influences efficacy of communication in a social insect. Am. Nat. 182, 834-840. doi: $10.1086 / 673712$ 
Greiner, B., Gadenne, C., and Anton, S. (2004). Three-dimensional antennal lobe atlas of the male moth, Agrotis ipsilon: a tool to study structure-function correlation. J. Comp. Neurol. 475, 202-210. doi: 10.1002/cne.20173

Guerenstein, P. G., and Hildebrand, J. G. (2008). Roles and effects of environmental carbon dioxide in insect life. Annu. Rev. Entomol. 53, 161-178. doi: 10.1146/annurev.ento.53.103106.093402

Hansson, B. S. (1995). Olfaction in lepidoptera. Experientia 51, 1003-1027.

Hansson, B. S., and Anton, S. (2000). Function and morphology of the antennal lobe: new developments. Annual Annu. Rev. Entomol. 45, 203-231. doi: 10.1146/annurev.ento.45.1.203

Hansson, B. S., Ljungberg, H., Hallberg, E., and Löfstedt, C. (1992). Functional specialization of olfactory glomeruli in a moth. Science 256, 1313-1315. doi: $10.1126 /$ science. 1598574

Hansson, B. S., and Stensmyr, M. (2011). Evolution of insect olfaction. Neuron 72, 698-711. doi: 10.1016/j.neuron.2011.11.003

Huetteroth, W., and Schachtner, J. (2005). Standard three-dimensional glomeruli of the Manduca sexta, antennal lobe: a tool to study both developmental and adult neuronal plasticity. Cell Tissue Res.319, 513-524. doi: 10.1007/s00441-004-1016-1

Ignell, R., Dekker, T., Ghaninia, M., and Hansson, B. S. (2005). Neuronal architecture of the mosquito deutocerebrum. J. Comp. Neurol. 493, 207-240. doi: 10.1002/cne.20800

Kent, K. S., Harrow, I. D., Quartararo, P., and Hildebrand, J. G. (1986). An accessory olfactory pathway in Lepidoptera: the labial pit organ and its central projections in Manduca sexta, and certain other sphinx moths and silk moths. Cell Tissue Res. 245, 237-245. doi: 10.1007/BF00213927

Kleineidam, C. J., Obermayer, M., Halbich, W., and Rössler, W. (2005). A macroglomerulus in the antennal lobe of leaf-cutting ant workers and its possible functional significance. Chem Senses. 30, 383-392. doi: $10.1093 /$ chemse/bji033

Koontz, M. A., and Schneider, D. (1987). Sexual dimorphism in neuronal projections from the antennae of silk moths (Bombyx mori, Antheraea polyphemus) and the gypsy moth (Lymantria dispar). Cell Tissue Res. 249, 39-50. doi: 10.1007/BF00215416

Koshihara, T., and Yamada, H. (1980). Attractant activity of the female sex pheromone of diamondback moth, plutella xylostella (1.), and analogue. Jap. J. Appl. Entomol. Z. 24, 6-12. doi: 10.1303/jjaez.24.6

Lee, J. K., and Altner, H. (1986). Primary sensory projections of the labial palppit organ of Pieris rapae L. (Lepidoptera: Pieridae). Int. J. Insect Morphol. 15, 439-448. doi: 10.1016/0020-7322(86)90036-X

Li, H., Horns, F., Wu, B., Xie, Q., Li, J., and Li, T., et al. (2017). Classifying drosophila olfactory projection neuron subtypes by singlecell RNA sequencing. Cell 171, 1206-1220. doi: 10.1016/j.cell.2017. 10.019

Li, Z., Feng, X., Liu, S. S., You, M., and Furlong, M. J. (2016). Biology, ecology, and management of the diamondback moth in china. Annu. Rev. Entomol. 61, 277-296. doi: 10.1146/annurev-ento-010715-023622

Ljungberg, H., Anderson, P., and Hansson, B. S. (1993). Physiology and morphology of pheromone-specific sensilla on the antennae of male and female Spodoptera littoralis, (Lepidoptera: Noctuidae). J. Insect Physiol. 39:253-260. doi: 10.1016/0022-1910(93)90096-A

Lopes, O., Barata, E. H., and Araujo, J. (2002). Fine structure of antennal sensilla basiconica and their detection of plant volatiles in the eucalyptus woodborer, Phoracantha semipunctata Fabricius (Coleoptera: Cerambycidae). Arthropod Struct. Dev. 31, 1-13. doi: 10.1016/S1467-8039(02)00011-7

Masante-Roca, I., Gadenne, C., and Anton, S. (2005). Three-dimensional antennal lobe atlas of male and female moths, Lobesia botrana (Lepidoptera: Tortricidae) and glomerular representation of plant volatiles in females. J. Exp. Biol. 208, 1147-1159. doi: 10.1242/jeb.01508

Namiki, S., Daimon, T., Iwatsuki, C., Shimada, T., and Kanzaki, R. (2014). Antennal lobe organization and pheromone usage in bombycid moths. Biol. Lett. 10:20140096. doi: 10.1098/rsbl.2014.0096

Ning, C., Yang, K., Xu, M., Huang, L. Q., and Wang, C. Z. (2016). Functional validation of the carbon dioxide receptor in labial palps of Helicoverpa armigera, moths. Insect Biochem. Mol. Biol. 73, 12-19. doi: 10.1016/j.ibmb.2016.04.002

Nirazawa, T., Fujii, T., Seki, Y., Namiki, S., Kazawa, T., and Kanzaki, R., et al. (2017). Morphology and physiology of antennal lobe projection neurons in the hawkmoth Agrius convolvuli. J. Insect Physiol. 98, 214-222. doi: 10.1016/j.jinsphys.2017.01.010.

Nishikawa, M., Nishino, H., Misaka, Y., Kubota, M., Tsuji, E., and Satoji, Y., et al. (2008). Sexual dimorphism in the antennal lobe of the ant Camponotus japonicus. Zoolog. Sci. 25, 195-204. doi: 10.2108/zsj.25.195.

Ochieng, S. A., Anderson, P., and Hansson, B. S. (1995). Antennal lobe projection patterns of olfactory receptor neurons involved in sex pheromone detection in Spodoptera littoralis (Lepidoptera: Noctuidae). Tissue Cell 27, 221-232. doi: 10.1016/S0040-8166(95)80024-7

Reisenman, C. E., Christensen, T. A., Francke, W., and Hildebrand, J. G. (2004). Enantioselectivity of projection neurons innervating identified olfactory glomeruli. J. Neurosci. 24, 2602-2611. doi: 10.1523/JNEUROSCI.5192-03.2004

Renwick, J. A. A., Haribal, M., Gouinguené, S., and Städler, E. (2006). Isothiocyanates stimulating oviposition by the diamondback moth, Plutella xylostella. J. Chem. Ecol. 32, 755-766. doi: 10.1007/s10886-006-9036-9

Rospars, J. P. (1983). Invariance and sex-specific variations of the glomerular organization in the antennal lobes of a moth, Mamestra brassicae, and a butterfly, Pieris brassicae. J. Comp. Neurol. 220, 80-96. doi: $10.1002 / \mathrm{cne} .902200108$

Rospars, J. P. (1988). Structure and development of the insect antennodeutocerebral system. Int. J. Insect Morphol. 17, 243-294. doi: 10.1016/0020-7322(88)90041-4

Rospars, J. P., and Hildebrand, J. G. (1992). Anatomical identification of glomeruli in the antennal lobes of the male sphinx moth Manduca sexta. Cell Tissue Res. 270, 205-227. doi: 10.1007/BF00328007

Rospars, J. P., and Hildebrand, J. G. (2000). Sexually dimorphic and isomorphic glomeruli in the antennal lobes of the sphinx moth Manduca sexta. Chem. Senses 25, 119-129. doi: 10.1093/chemse/25.2.119

Rossi Stacconi, M. V., Hansson, B. S., Rybak, J., and Romani, R. (2014). Comparative neuroanatomy of the antennal lobes of 2 homopteran species. Chem. Senses 39, 283-294. doi: 10.1093/chemse/bjt114

Sadek, M. M., Hansson, B. S., Rospars, J. P., and Anton, S. (2002). Glomerular representation of plant volatiles and sex pheromone components in the antennal lobe of the female Spodoptera littoralis. J. Exp. Biol. 205, 1363-1376.

Sarfraz, M., Keddie, A. B., and Dosdall, L. M. (2005). Biological control of the diamondback moth, Plutella xylostella: a review. Biocontrol Sci. Techn. 15, 763-789. doi: 10.1080/09583150500136956

Seki, Y., Dweck, H. K., Rybak, J., Wicher, D., Sachse, S., and Hansson, B. S. (2017). Olfactory coding from the periphery to higher brain centers in the Drosophila brain. BMC Biol. 15:56. doi: 10.1186/s12915-017-0389-Z

Solari, P., Corda, V., Sollai, G., Kreissl, S., Galizia, C. G., and Crnjar, R. (2016). Morphological characterization of the antennal lobes in the Mediterranean fruit fly Ceratitis capitata. J. Comp. Physiol. A 202, 131-146. doi: 10.1007/s00359-015-1059-7

Stange, G. (1992). High resolution measurement of atmospheric carbon dioxide concentration changes by the labial palp organ of the moth Heliothis armigera (Lepidoptera: Noctuidae). J. Comp. Physiol. A 171, 317-324. doi: 10.1007/BF00223962

Sun, L., Xiao, H. J., Gu, S. H., Guo, Y. Y., Liu, Z. W., and Zhang, Y. J. (2014). Perception of potential sex pheromones and host-associated volatiles in the cotton plant bug, Adelphocoris fasciaticollis, (Hemiptera: Miridae): morphology and electrophysiology. Appl. Entomol. Zool. 49, 43-57. doi: 10.1007/s13355-013-0223-1

Todd, J. L., Haynes, K. F., and Baker, T. C. (1992). Antennal neurones specific for redundant pheromone components in normal and mutant Trichoplusia ni males. Physiol. Entomol. 17, 183-192. doi: 10.1111/j.1365-3032.1992.tb01198.x

Trible, W., Olivoscisneros, L., Mckenzie, S. K., Saragosti, J., Chang, N. C., and Matthews, B. J., et al. (2017). orco mutagenesis causes loss of antennal lobe glomeruli and impaired social behavior in ants. Cell 170, 727-735. doi: 10.1016/j.cell.2017.07.001

Trona, F., Anfora, G., Bengtsson, M., Witzgall, P., and Ignell, R. (2010). Coding and interaction of sex pheromone and plant volatile signals in the antennal lobe of the codling moth Cydia pomonella. J. Exp. Biol. 213, 4291-4303. doi: 10.1242/jeb.047365.

Varela, N., Couton, L., Gemeno, C., Avilla, J., Rospars, J. P., and Anton, S. (2009). Three-dimensional antennal lobe atlas of the oriental fruit moth, Cydia molesta (busck) (Lepidoptera: Tortricidae): comparison of male and female glomerular organization. Cell Tissue Res. 337, 513-526. doi: 10.1007/s00441-009-0839-1 
Vosshall, L., and Wong, A. R. (2000). An olfactory sensory map in the fly brain. Cell 102, 147-159. doi: 10.1016/S0092-8674(00)00021-0

Wang, X., Khakame, S. K., Ye, C., Yang, Y., and Wu, Y. (2013). Characterisation of field-evolved resistance to chlorantraniliprole in the diamondback moth, Plutella xylostella, from china. Pest Manag. Sci. 69, 661-665. doi: 10.1002/ps.3422

Wu, B., Li, J., Chou, Y. H., Luginbuhl, D., and Luo, L. (2017). Fibroblast growth factor signaling instructs ensheathing glia wrapping of Drosophila olfactory glomeruli. Proc. Natl. Acad. Sci. U S A. 114, 7505-7512. doi: 10.1073/pnas.1706533114

Xu, M., Guo, H., Hou, C., Wu, H., Huang, L. Q., and Wang, C. Z. (2016). Olfactory perception and behavioral effects of sex pheromone gland components in Helicoverpa armigera and Helicoverpa assulta. Sci. Rep. 6:22998. doi: $10.1038 /$ srep22998

Yan, X. Z., Deng, C. P., Sun, X. J., and Hao, C. (2014). Effects of various degrees of antennal ablation on mating and oviposition preferences of the diamondback moth, Plutella xylostella L. J. Integr. Agr. 13, 1311-1319. doi: 10.1016/S2095-3119(14)60762-0

Yan, X. Z., Deng, C. P., Xie, J. X., Wu, L. J., Sun, X. J., and Hao, C. (2017a). Distribution patterns and morphology of sensilla on the antennae of Plutella xylostella (L.) -A scanning and transmission electron microscopic study. Micron 103, 1-11. doi: 10.1016/j.micron.2017. 08.002
Yan, X. Z., Xie, J. X., Deng, C. P., Lan-Jun, W. U., Sun, X. J., and Hao, C., et al. (2017b). Number,distribution and morphology of cell bodies in the antennal lobe of Plutella xylostella (Lepidoptera: Plutellidae) adults. Acta Entomologica Sinica. 60, 735-741. doi: 10.16380/j.kcxb.2017.07.001

Zhao, X. C., Chen, Q. Y., Guo, P., Xie, G. Y., Tang, Q. B., Guo, X. R., et al. (2016). Glomerular identification in the antennal lobe of the male moth Helicoverpa armigera. J. Comp. Neurol. 524, 2993-3013. doi: 10.1002/cne.24003

Zhao, X. C., Tang, Q. B., Berg, B. G., Liu, Y., Wang, Y. R., Yan, F. M., et al. (2013). Fine structure and primary sensory projections of sensilla located in the labialpalp pit organ of Helicoverpa armigera (Insecta). Cell Tissue Res. 353, 399-408. doi: $10.1007 / \mathrm{s} 00441-013-1657-\mathrm{z}$

Conflict of Interest Statement: The authors declare that the research was conducted in the absence of any commercial or financial relationships that could be construed as a potential conflict of interest.

Copyright (๑) 2019 Yan, Wang, Xie, Deng, Sun and Hao. This is an open-access article distributed under the terms of the Creative Commons Attribution License (CC $B Y)$. The use, distribution or reproduction in other forums is permitted, provided the original author(s) and the copyright owner(s) are credited and that the original publication in this journal is cited, in accordance with accepted academic practice. No use, distribution or reproduction is permitted which does not comply with these terms. 